\title{
Giant Solitary Anterior Cervical Canal Neurofibroma: Case Report and Surgical Technique
}

\author{
Olufemi Emmanuel Idowu ${ }^{1}$, Kazeem M. Atobatele ${ }^{1}$, Sunday O. Soyemi ${ }^{2}$ \\ ${ }^{1}$ Neurosurgery Division, Department of Surgery, Lagos State University College of Medicine \\ and Lagos State University Teaching Hospital, Lagos, Nigeria \\ ${ }^{2}$ Department of Pathology and Forensic Medicine, Lagos State University Teaching Hospital, Lagos, Nigeria
}

Giant solitary anterior cervical canal neurofibroma (GSACCN) is rarely reported in the literature. When the large lesion is ventrally located to the spinal cord, an anterolateral approach may not be ideal due to various technical challenges. In this report, we describe a case of intradural extramedullary GSACCN located at the cervical region extending from the axis to the sixth cervical vertebrae. Here we also describe a posterior technique successfully used to resect the tumour. Therefore, the posterior approach by en bloc decompressive laminectomy and laminoplasty might be used to adequately treat the lesion.

Keywords: Laminectomy; Laminoplasty; Neurofibroma

\section{Introduction}

Spinal nerve sheath tumours are usually intradural and extramedullary tumours arising from the dorsal sensory roots. Together with meningiomas, they constitute approximately $90 \%$ of all intradural extramedullary tumours [1]. Spinal nerve sheath tumours include the most frequent spinal schwannoma (65\% of intradural extramedullary nerve sheath tumours and $30 \%$ of all intradural extramedullary lesions) [2,3], the less frequent spinal neurofibroma [3], and the least frequent spinal ganglioneuroma [3].

Neurofibromas (NFs) are benign tumours that are composed of Schwann cells and fibroblasts [1]. They typically occur either as solitary lesions or as part of generalized syndromes of neurofibromatosis generally known as NF type 1 (von Recklinghausen disease) [3]. NFs are histologically identical to those seen in NF type 1 [4-6]. When arising from spinal nerve roots, they are usually localized to the cervical region. As they slowly grow, they could remodel the adjacent bone, often resulting in widening of the neural exit foramen but thinning of the pedicle, lamina, and posterior vertebral body scalloping.

Giant spinal canal NFs are rarely reported in literature. In 1992, Egelhoff et al. [7] reported a large intraspinal neurofibroma in a lumbar region. In 2003, Garg et al. [8] reported multiple cervical NFs extending from occiput to C6 in a 10-year-old boy who presented with quadriplegia. Large cervical canal solitary NFs which are not related to NFs type 1 has not been reported previously. Here, we present the case of a patient with giant anterior cervical

Received Jul 18, 2014; Revised Aug 2, 2014; Accepted Aug 3, 2014

Corresponding author: Olufemi Emmanuel Idowu

Neurosurgery Division, Department of Surgery, Lagos State University College of Medicine and Lagos State University Teaching Hospital, 1-5 Oba Akinjobi Road, Ikeja, Lagos, Nigeria Tel: +234-08023451369, E-mail: oeidowu412@yahoo.com 
solitary NFs that was removed via a posterior approach. The surgical technique for successful tumour excision is also described in this report.

The study followed principles in the Declaration of Helsinki.

\section{Technical Note}

\section{Case presentation}

The patient was a 32-year-old right-handed male driver. He presented with neck pain and worsening quadriparesis culminating in his inability to walk for 1 year. The upper cervical pain was mild to moderate in intensity with worse pain when coughing and sneezing. His weakness was gradual onset, initially involving the lower extremities (worse on the left) prior to involving his upper extremities. The weakness became progressive until he could not ambulate independently. He had history of impaired sensation in all limbs and torso, constipation, urinary urgency, and hesitancy. However, he had no history of antecedent spinal trauma, loss of weight, chronic cough or tuberculosis.

Medical examination revealed that he was a conscious man who was afebrile, not pale, and anicteric. His mental status was normal. There was no spinal tenderness or deformity, subcutaneous nodules, café-au-lait spots, axillary/ inguinal freckling, or iris harmatomas. Motor examination revealed muscle atrophy in all his limbs with power grade of $2-3 / 5$. There was significant spasticity in all his extremities with exaggerated muscle stretch reflexes, clonus and extensor plantar reflexes. Sensory examination revealed diminution of pain and touch from the second cervical to fourth and fifth sacral dermatome.

Cervical 1.5 T magnetic resonance imaging showed an intradural and extramedullary tumour ventral to the spinal cord extending from the axis to the sixth cervical vertebrae, with the adjoining cord thinned and pushed posteriorly (Fig. 1). Subsequently he had an uneventful total tumour resection. Postoperative period was also uneventful with progressive neurological improvement with neurorehabilitation. Resected specimen histology was consistent with NFs (Fig. 2).

\section{Techniques}

A posterior approach was selected for the resection. En bloc resection of the posterior elements was performed from the axis to the sixth cervical vertebrae. The theca was opened via a longitudinal left paramedian incision. The ipsilateral dentate ligaments were sectioned. The cord was then gently rotated to the contralateral side to allow exposure of the ventrolateral surface. Intraoperative finding revealed a globular tumour arising from the left second dorsal nerve root with thinning of the posterior vertebrae elements. The tumour was then resected completely (Figs. $3,4)$. Primary duroplasty was performed and bilateral open-door laminoplasty was operated at second, fourth, and sixth cervical level.

\section{Discussion}

Almost all intradural and intramedullary spinal nerve root tumours are schwannomas or NFs [3]. In most in-

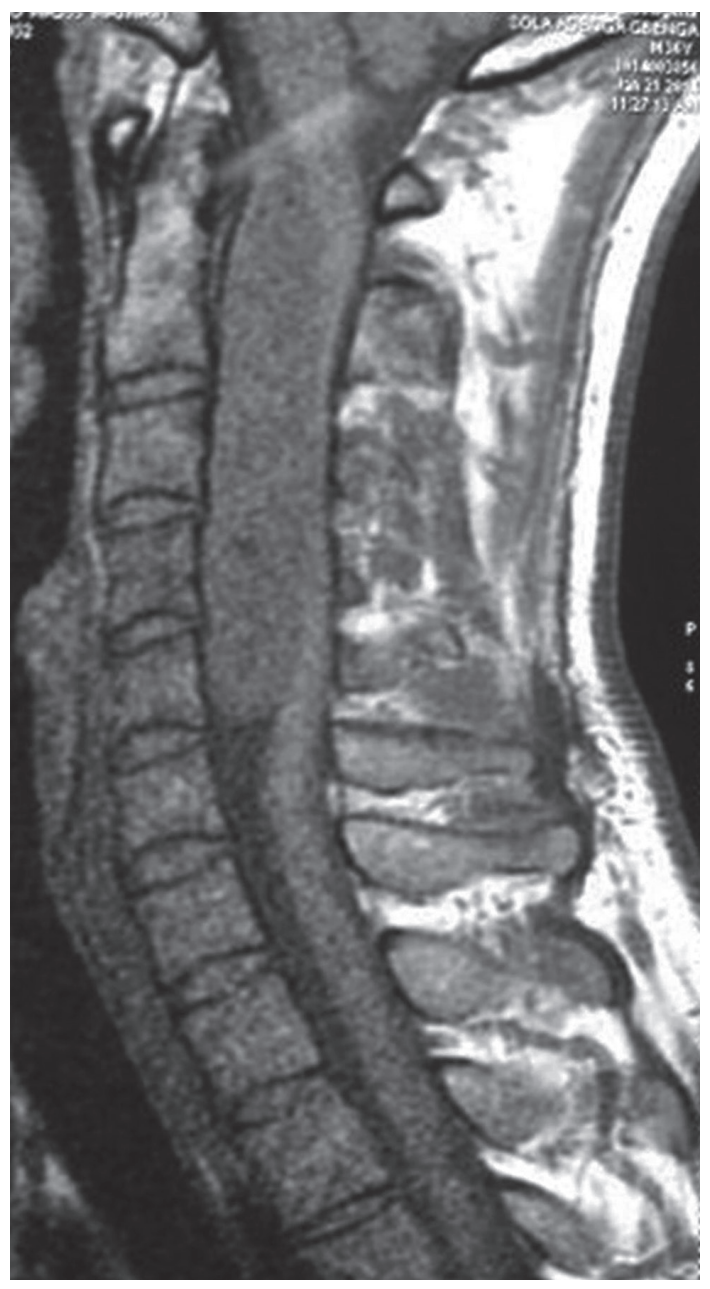

Fig. 1. Preoperative T1-weighted magnetic resonance image of the patient. 

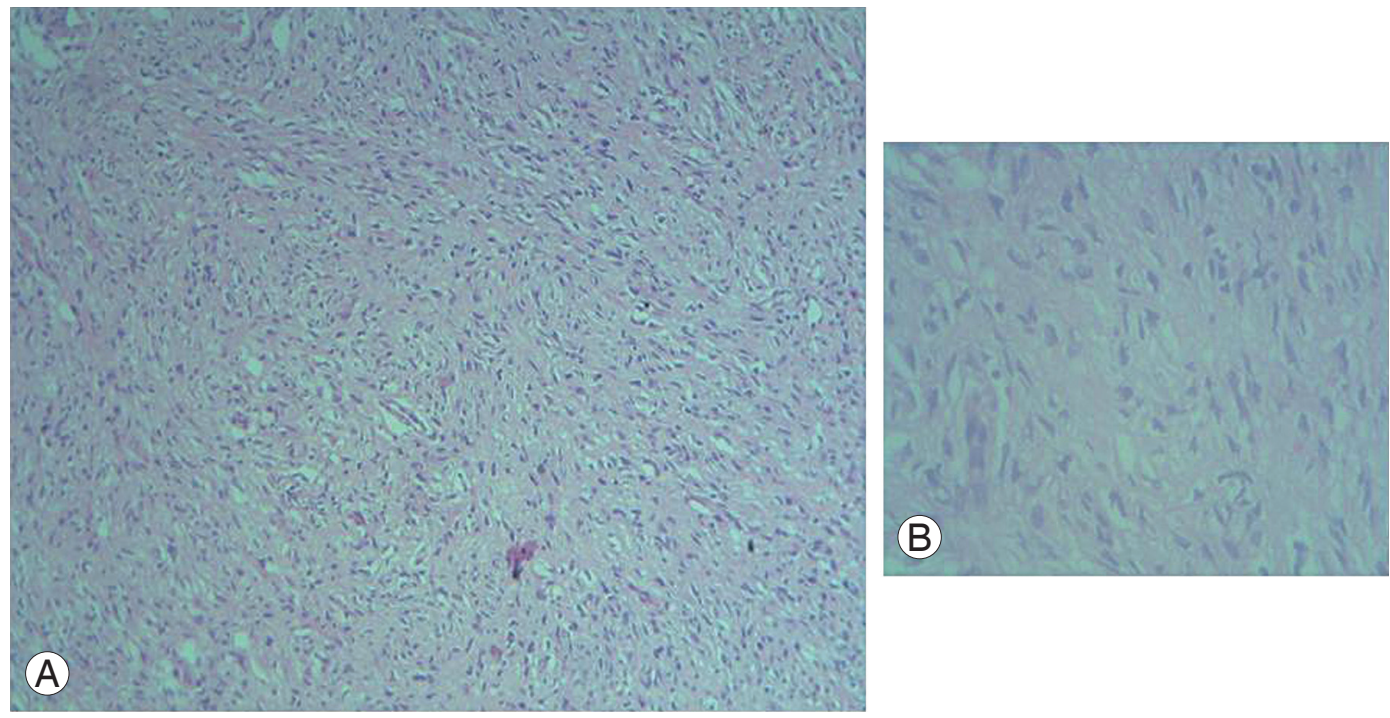

Fig. 2. Microscopic examination of the tumour with H\&E stain showing proliferation of fibroblasts, Schwann cells and neurites in a disorderly fashion within a myxoid background, $\times 40$ magnification (A) and $\times 400$ magnification (B) showing predominantly Schwann cells with elongated spindle-shaped nuclei on a myxoid background.

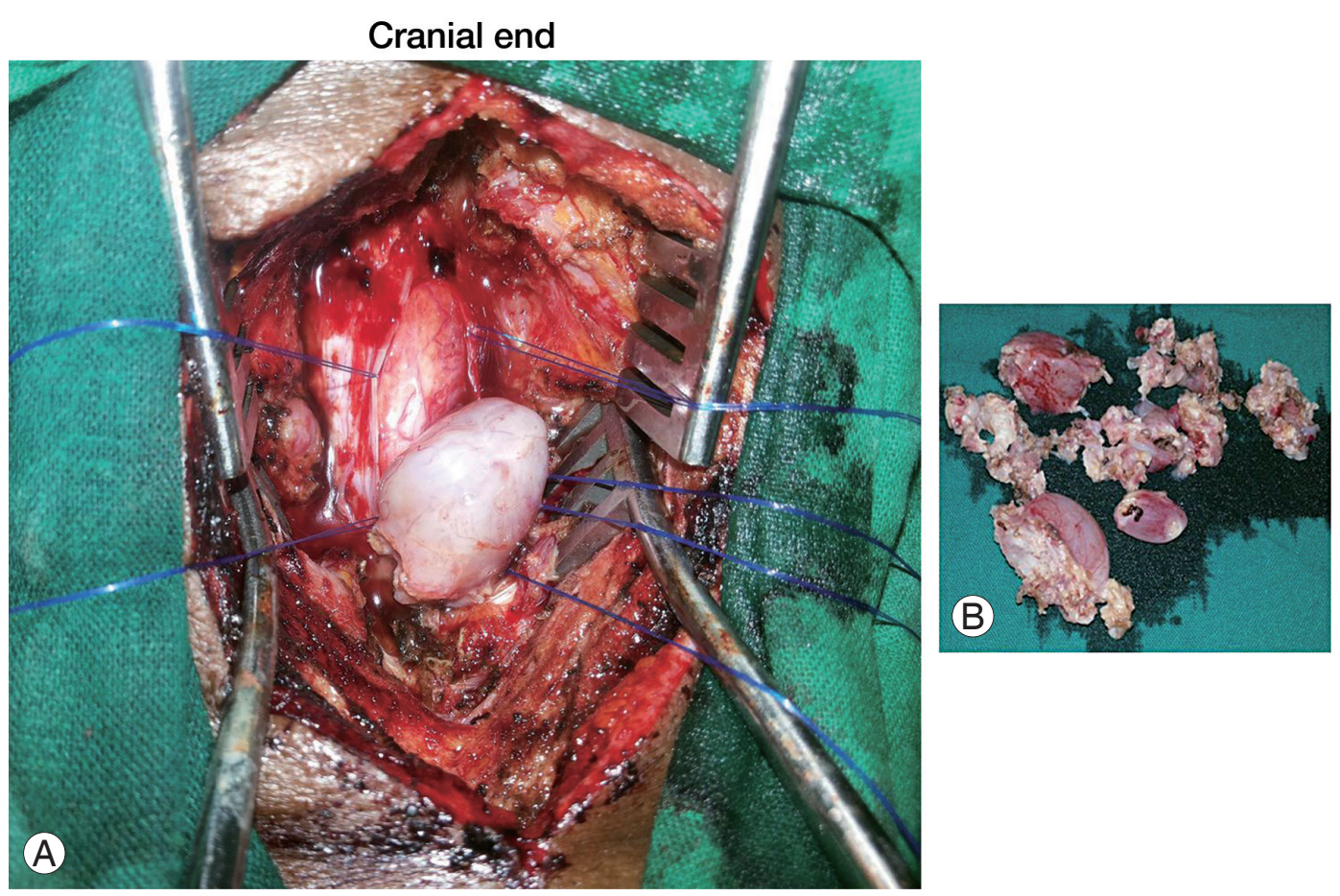

\section{Caudal end}

Fig. 3. Intraoperative tumour being resected (A) and pieces of tumour removed (B).

stances, intraspinal schwannomas are indistinguishable from NFs [4]. Spinal nerve sheath tumours are relatively common in neurofibromatosis. In 1999, Thakkar et al. [9] found spinal tumour NFs in $65 \%$ of 54 neurofibromatosis patients examined with magnetic resonance imaging.
Spinal nerve sheath tumours are more common in symptomatic than asymptomatic patients [9]. Different level of the spine can be similarly affected. Tatagiba et al. [10] reported that the cervical region was the most commonly area, followed by thoracic and lumbar area. However, gi- 


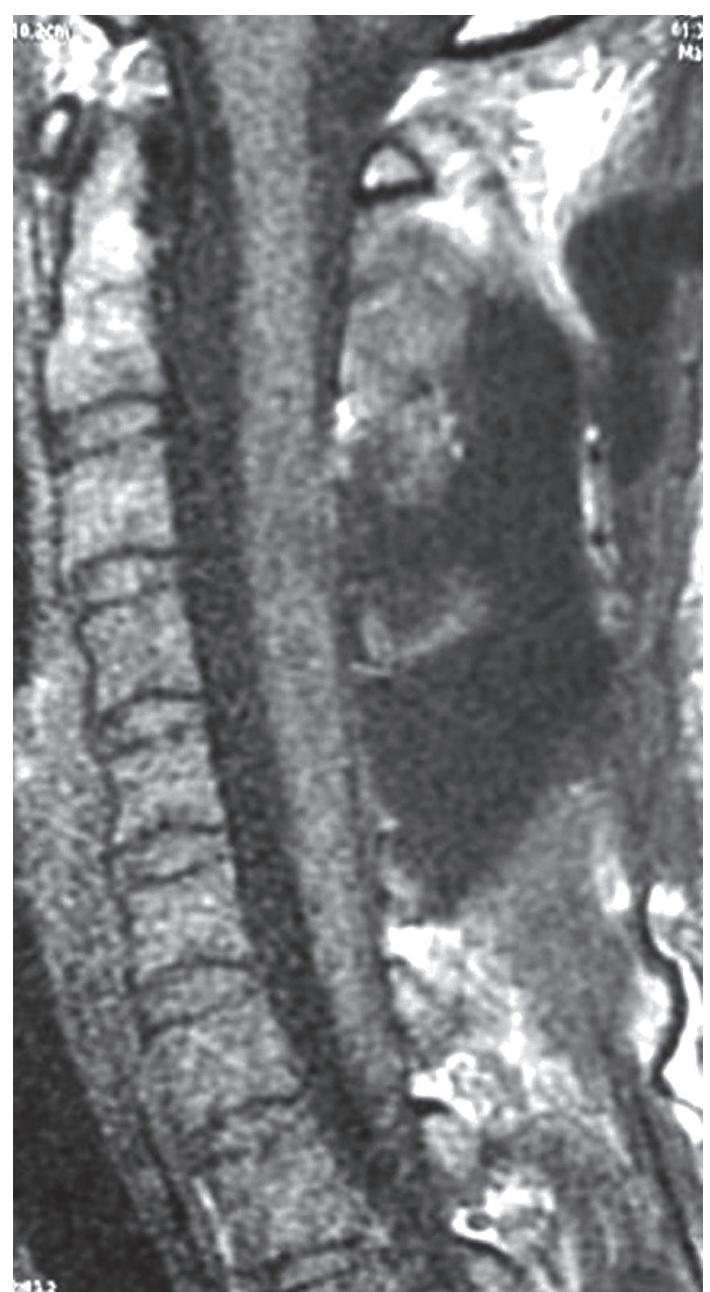

Fig. 4. Postoperative T1-weighted magnetic resonance image of the patient.

ant solitary NFs of the spinal canal as described in this report are rare.

Most NFs are solitary, sporadic, and slow growing in patients commonly presenting pain with peak presentation between 20 and 30 years of age without sex predilection [11]. As NFs usually arise from the dorsal sensory roots, radicular sensory changes also occur. Myelopathy may occur if the lesion is too large. Our patient had quadriparesis involving bladder and bowel due to the large size of the lesion (axis to the sixth cervical vertebrae) which significantly compressed the spinal cord.

Surgical goals in intraspinal lesions are to decompress the spinal cord, prevent local recurrence, reconstruct the spine, and provide immediate stabilization. Surgical approaches for spinal tumours depend on many variables, including the surgeon's preference, the location of the mass, extent of the tumour within the canal, patient's medical health and overall prognosis. Giant cervical spinal cord tumours located anteriorly to the spinal cord may require an extensive anterior vertebrectomy approach for their removal followed by stabilization and bony fusion if they are to be approached anteriorly. To minimize the invasiveness of the conventional anterior approach, we utilized the posterior approach with laminoplasty. Posterior approaches, starting with the decompressive laminectomy, have traditionally been the most common surgical procedures for spinal cord tumours [12]. The posterior approach has been reported to affect the spinal integrity to a much lesser degree [12]. However, this approach should only be used if there is no risk of concomitant instability. In this case report, cervical stability was not compromised by the use of this approach as the anterior and posterior longitudinal ligaments, discs, capsular ligaments, as well as the facets were not disrupted. The posterior approach used in this case report also avoided a staged procedure, which resulted in additional advantages such as reduction of operation time, morbidity, and hospital stay. However, this posterior approach has its limitations, including poor visualization of the tumour immediately anterior to the spinal cord and the need to manipulate the spinal cord to completely remove a tumour related to the dura [12].

\section{Conflict of Interest}

No potential conflict of interest relevant to this article was reported.

\section{References}

1. Tsui EY, Peh WC, Htoo MM. Clinics in diagnostic imaging (76): left extradural-intradural lumbar neurofibroma. Singapore Med J 2002;43:433-8.

2. Abul-Kasim K, Thurnher MM, McKeever P, Sundgren PC. Intradural spinal tumors: current classification and MRI features. Neuroradiology 2008;50:30114.

3. El-Mahdy W, Kane PJ, Powell MP, Crockard HA. Spinal intradural tumours: Part I. extramedullary. Br J Neurosurg 1999;13:550-7.

4. Dickersin GR. The electron microscopic spectrum of nerve sheath tumors. Ultrastruct Pathol 1987;11:10346.

5. Peltonen J, Jaakkola S, Virtanen I, Pelliniemi L. Peri- 
neurial cells in culture: an immunocytochemical and electron microscopic study. Lab Invest 1987;57:4808.

6. Weiss SW, Goldman JR. Neurofibroma. In: Weiss SW, Goldman JR, editors. Enzinger and Weiss's soft tissue tumors. 4th ed. St Louis: Mosby; 2001. p.1122-46.

7. Egelhoff JC, Bates DJ, Ross JS, Rothner AD, Cohen BH. Spinal MR findings in neurofibromatosis types 1 and 2. AJNR Am J Neuroradiol 1992;13:1071-7.

8. Garg S, Hosalkar H, Dormans JP. Quadriplegia in a 10 year-old boy due to multiple cervical neurofibromas. Spine (Phila Pa 1976) 2003;28:E339-43.

9. Thakkar SD, Feigen U, Mautner VF. Spinal tumours in neurofibromatosis type 1: an MRI study of fre- quency, multiplicity and variety. Neuroradiology 1999;41:625-9.

10. Tatagiba M, Bini W, Sepehrnia A, Eichhorn R, Kleider A, Samii M. Involvement of spinal nerves in neurofibromatosis. Neurosurg Rev 1994;17:43-9.

11. Pilavaki M, Chourmouzi D, Kiziridou A, Skordalaki A, Zarampoukas T, Drevelengas A. Imaging of peripheral nerve sheath tumors with pathologic correlation: pictorial review. Eur J Radiol 2004;52:229-39.

12. St Clair SF, McLain RF. Posterolateral spinal cord decompression in patients with metastasis: an endoscopic assisted approach. Surg Technol Int 2006;15:257-63. 